\title{
Endoscopic retrieval of a migrated stent after endoscopic ultrasound-guided choledochoduo- denostomy
}

Use of endoscopic ultrasound-guided choledochoduodenostomy (EUS-CDS) is reported with increasing frequency [1]. While stent migration into the bile duct is a possible complication of EUS-CDS, it has not previously been reported. We describe a case of complete stent migration into the bile duct, where the stent was successfully retrieved by inserting an endoscope directly into the bile duct after balloon dilation of the duodenal fistula.

A 73-year-old woman presented to our institution with recurrent cholangitis due to a congenital choledochal cyst. She underwent percutaneous transhepatic biliary drainage (PTBD) after failed biliary cannulation during endoscopic retrograde cholangiopancreatography. However, she could no longer tolerate the PTBD tube. Thus EUS-CDS was performed via the duodenal bulb followed by placement of two double-pigtail stents. After 1 month, the woman developed acute cholangitis. Urgent endoscopy revealed that one of the biliary stents had migrated completely into the bile duct.

The migrated stent could not be grasped under fluoroscopic guidance. A guide wire was passed through the choledochoduodenal fistula along the remaining stent, and the fistula was dilated with a $15-\mathrm{mm}$ dilation balloon (CRE; Boston-Scientific, Natick, Massachusetts, USA; Fig. 1). Then an endoscope was directly advanced into the bile duct through the dilated fistula. Direct cholangioscopy revealed that the two double-pigtail stents were entwined with each other ( $\bullet$ Fig. 2). Under endoscopic guidance, the stents were disentangled using a forceps. Then the distal end of the migrated stent was grasped with a snare ( $\bullet$ Fig. 3 ) and pulled from the bile duct to the duodenal bulb ( Fig. 4, Video 1). No procedure-related complications occurred, and the patient was discharged after the PTBD tube had been removed.

The management of stent migration after EUS-CDS is technically more challenging than endoscopic removal of a migrated stent via the papilla [2-4]. Transmural direct cholangioscopy through the choledochoduodenostomy fistula was effective for retrieving the migrated stent.

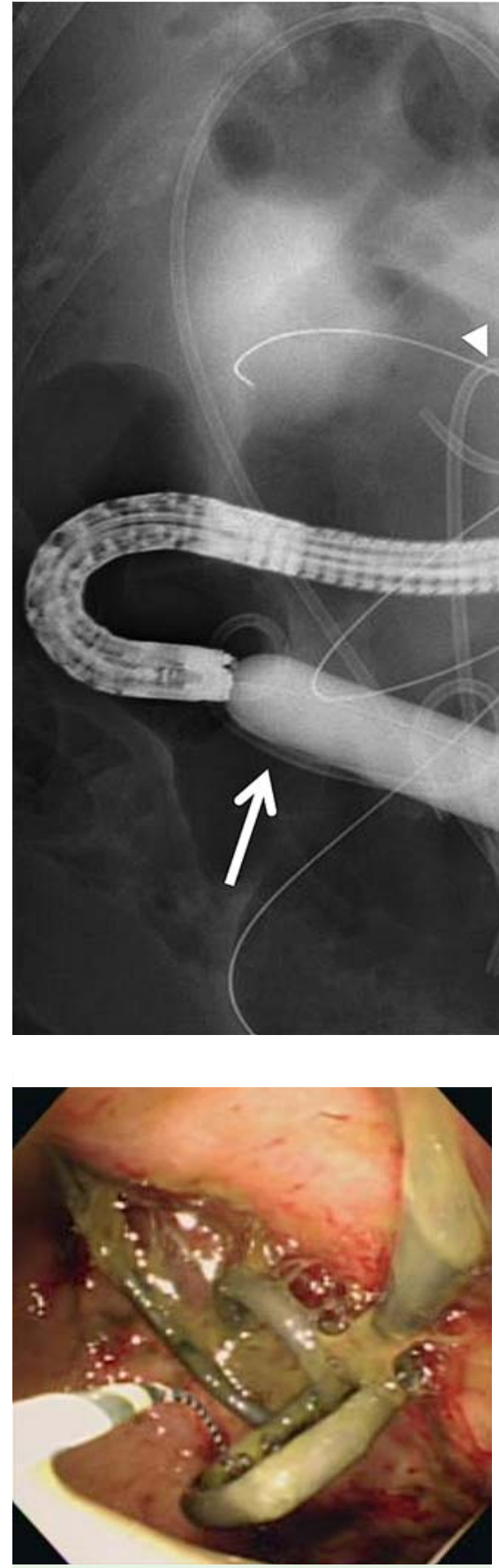

Fig. 2 Direct endoscopy showing the two entwined stents in the bile duct.
Fig. 1 Fluoroscopy showing balloon dilation of the choledochoduodenostomy fistula beside the remaining stent (arrow). The arrowhead indicates the migrated stent. 


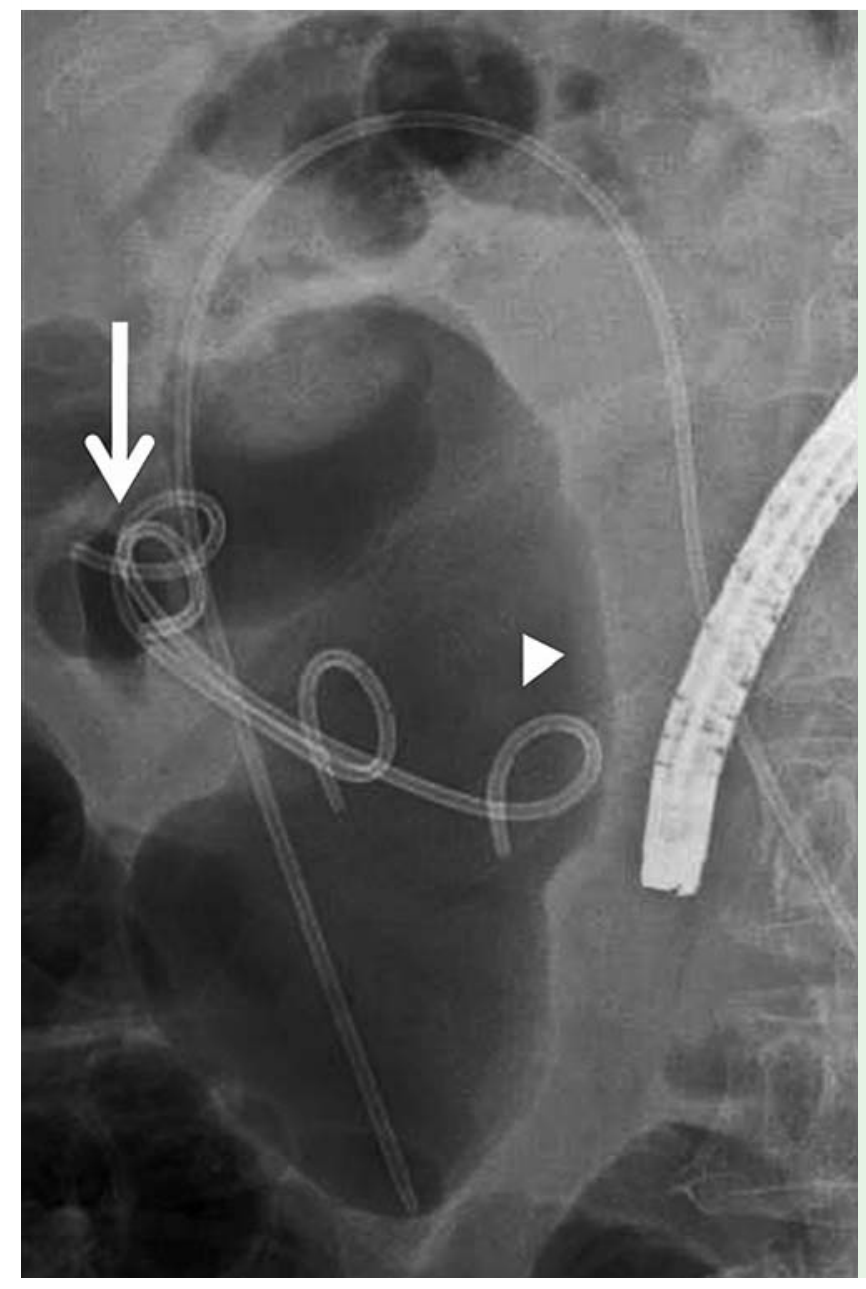

Fig. 4 Fluoroscopy showing two doublepigtail stents located between the bile duct and duodenal bulb. The arrow indicates the duodenal side, and the arrowhead the bile duct side.

\section{Video 1}

Fluoroscopic imaging showing that the doublepigtail stent had migrated inside the bile duct. Following balloon dilation of the choledochoduodenostomy fistula, an endoscope was advanced into the bile duct. Then the entwined double-pigtail stents were disentangled with a forceps, and the distal end of the migrated stent was grasped with a snare. Finally, the migrated stent was extracted from the bile duct to the duodenal bulb.

\section{References}

1 Hara K, Yamao K, Niwa $Y$ et al. Prospective clinical study of EUS-guided choledochoduodenostomy for malignant lower biliary tract obstruction. Am J Gastroenterol 2011 in press

2 Okabe Y, Tsuruta O, Kaji R et al. Endoscopic retrieval of migrated plastic stent into bile duct or pancreatic pseudocyst. Dig Endosc 2009; 21: $1-7$

3 Lahoti S, Catalano MF, Geenen JE et al. Endoscopic retrieval of proximally migrated biliary and pancreatic stents: experience of a large referral center. Gastrointest Endosc 1998; 47: 486-491

4 Johanson JF, Schmalz MJ, Geenen JE. Incidence and risk factors for biliary and pancreatic stent migration. Gastrointest Endosc 1992; 38: $341-346$

\section{Bibliography}

DOI $10.1055 / \mathrm{s}-0030-1256731$

Endoscopy 2011; 43: E370 - E371

(c) Georg Thieme Verlag KG Stuttgart · New York . ISSN 0013-726X

\section{Corresponding author \\ Kazumichi Kawakubo, MD}

Department of Gastroenterology

Graduate School of Medicine

The University of Tokyo

7-3-1 Hongo

Bunkyo-ku

Tokyo 113-8655

Japan

Fax: +81-3-38140021

kkawakubo-gi@umin.ac.jp 